\title{
MODELING OF PROCESS OF MELTING OF ELECTRODES WITH EXOTHERMAL MIXTURE IN COATING DURING REPAIR WELDING AND SURFACING
}

\author{
A.M. KUSHCHY and A.F. VLASOV \\ Donbas State Machine Building Academy \\ 72 Shkadinov Str., 84313, Kramatorsk, Donetsk region, Ukraine. E-mail: dgma@dgma.donetsk.ua
}

\begin{abstract}
Application of high-production electrodes in welding-up of casting defects and repair of stands is still relevant up to present moment. Efficiency of surfacing process can be increased by using exothermal mixtures in coating. The work studies the possibility of optimizing fusion of electrode coating with iron powder containing scale of rolling industry and aluminum powder. Statistical model was proposed allowing optimizing content of exothermal mixture in coating for minimizing loss of electrode metal. 6 Ref., 6 Figures.
\end{abstract}

Keywords: arc welding and surfacing, repair, coated electrodes, exothermal mixture, electrode melting, simulation

Coated-electrode arc welding and surfacing is one of the efficient methods of repair in welding-up of casting defects and cracks of stands of metalworking machines. At that, entering up to $70 \%$ of iron powder in electrode coating composition at simultaneous increase of its thickness can result in rise of efficiency. Introduction of significant amount of iron powder in electrode coatings promotes for reduction of their plasticity and process complication due to non-uniform fusion of rod and coating, formation of such called nose, which results in unsatisfactory weld formation and arc extinction.

Uniformity of fusion of electrode rod and coating can be reasonably provided by application of effect of exothermal reactions [1]. Thermit welding is tending to reach higher temperatures, therefore, thermit mixtures are manufactured based on iron oxide. Results of calculation of temperature of scale and its constituents during reaction with aluminum powder showed that using roll scale instead of scale of forge-and-press production at small difference in heat emission promotes for reduction of larger amount of iron. This has positive effect not only on uniformity of fusion of electrode coating and rod, but also on quality of deposited metal and allows selecting scale of rolling production and aluminum powder as base components for exothermal reaction [2].

Aim of preset work is optimizing parameters of fusion of electrode coating with exothermal mixture consisting of scale of rolling production and aluminum powder.

Simulation of fusion process is carried out using Statistica 6 [3-6] software complex. Experimental realizing of the designs is performed by means of determination of coefficient of deposition and loss of electrode metal. Parameters being varied are the content of exothermal mixture in

\begin{tabular}{|c|c|c|c|c|c|c|}
\hline \multirow[b]{2}{*}{ Factor } & \multicolumn{6}{|c|}{$\begin{array}{l}\text { Regr. Coefficients; Var.:AH; R-sql=,93047; Adj; ,39357 (Spreadsheet9) } \\
2 \text { factors, } 1 \text { Blocks, } 10 \text { Runs; MS Residual=2,487993 } \\
\text { DV: AH }\end{array}$} \\
\hline & $\begin{array}{c}\text { Regressn } \\
\text { Coeff. }\end{array}$ & Std. Err. & $\mathrm{t}(4)$ & $p$ & $\begin{array}{c}-95, \% \\
\text { Cnf.Limt } \\
\end{array}$ & $\begin{array}{c}+95, \% \\
\text { Cnf.Limt }\end{array}$ \\
\hline Mean/interc. & 6,91111 & 3,160179 & 1,71089 & 0,016227 & $-3,36734$ & 14,18079 \\
\hline (1)Q(L) & 0,13958 & 0,158751 & 0,65771 & 0,044665 & $-0,33635$ & 0,54517 \\
\hline $\mathrm{Q}(\mathrm{Q})$ & $-0,00083$ & 0,002399 & 0,21521 & 0,008401 & $-0,00614$ & 0,00718 \\
\hline (2)D(L) & 1,02500 & 3,175017 & 2,35885 & 0,007776 & $-1,32586$ & 16,30466 \\
\hline $\mathrm{D}(\mathrm{Q})$ & $-0,01603$ & 0,959621 & $-1,80210$ & 0,014588 & $-4,39367$ & 0,93500 \\
\hline $1 \mathrm{~L}$ by $2 \mathrm{~L}$ & 0,00901 & 0,039433 & $-2,50422$ & 0,006647 & $-0,20823$ & 0,01073 \\
\hline
\end{tabular}

Figure 1. Analysis of experiment design-matrix (model 1) 


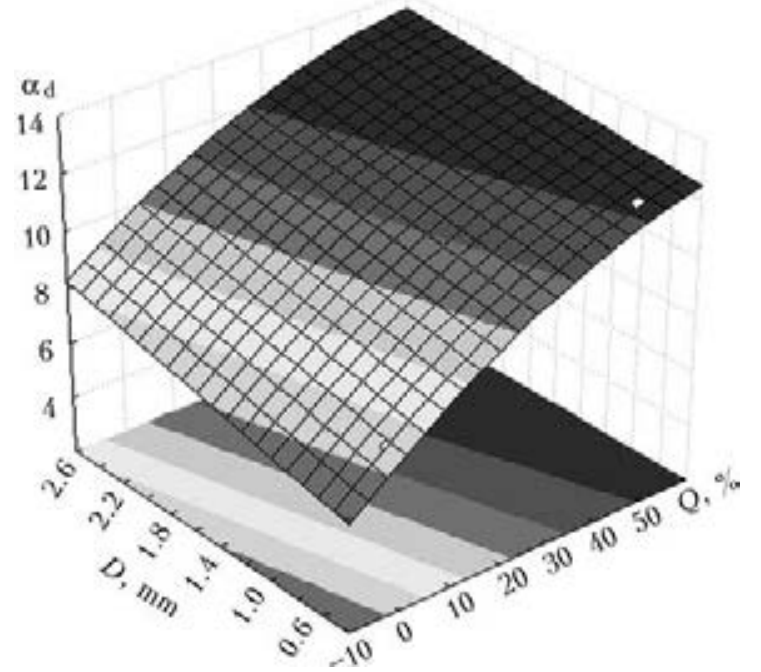

Figure 2. Dependence of deposition coefficient $\alpha_{\mathrm{d}}$ on amount of exothermal mixture $Q$ and thickness of electrode coating $D$

the coating of electrodes $N_{\text {ex.m }}$, amount of scale portion in relation to portion of aluminum pow$\operatorname{der} A$ and thickness of electrode coating $D$.

Experiments with factors varying at two levels, i.e. experiments of $2^{k}$ type, have found the largest distribution. Rise of number of factors and variation levels sharply increases number of experiments, therefore, orthogonal designs of the second order $2^{2}$ were used [6]. Mathematical models were designed describing effect of the following pairs of factors on deposition coefficient and electrode metal loss coefficient. They are content of exothermal mixture in electrode coating $N_{\text {ex.m }}$ and thickness of electrode coating $D$, amount of scale portion in relation to portion of aluminum powder $A$ and thickness of electrode coating $D$.

Model 1. Factors: amount of exothermal mixture $Q$ and thickness of electrode coating $D$. Response is the deposition coefficient $\alpha_{\mathrm{d}}$. Figure 1 shows analysis of experiment plan-matrix.

It is seen from Figure 1 that all members of the model have statistically significant effects (level $p<0.05$ ). It also gives value of approxi-

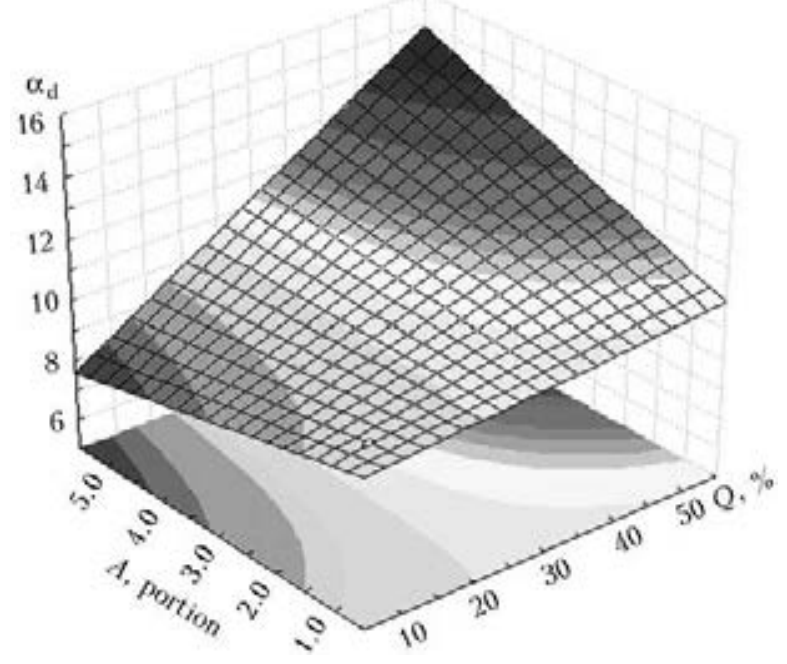

Figure 4. Dependence of surfacing coefficient $\alpha_{\mathrm{d}}$ on amount of exothermal mixture $Q$ and amount of scale portion $A$

mation reliability $R$-sqr $=0.93047-$ general quality of the model is good. Calculation of coefficients of regression is represented in the first column; $t$ (4) is the observed values of Student's criterion; $p$ is the significance of coefficients on Student's criterion; two last columns are the intervals for coefficients.

Regression equation looks like:

$$
\begin{gathered}
\alpha_{d}=6.911111+0.139500 Q-0.000827 Q^{2}+ \\
+1.025000 D-0.016667 D^{2}-0.009000 Q D .
\end{gathered}
$$

Figure 2 shows response surface.

Model 2. Factors: amount of exothermal mixture $Q$ and amount of scale portion in relation to aluminum $A$; response is the deposition coefficient $\alpha_{d}$. Figure 3 shows analysis of experiment plan-matrix.

It is seen from Figure 3 that all members of the model have statistically significant effects (level $p<0.05$ ). It also gives value of approximation reliability $R$-sqr $=0.98857-$ general quality of the model is good. Calculation of coefficients of regression is represented in the first column; $t(3)$ is the observed values of Student's criterion; $p$ is the significance of coefficients on

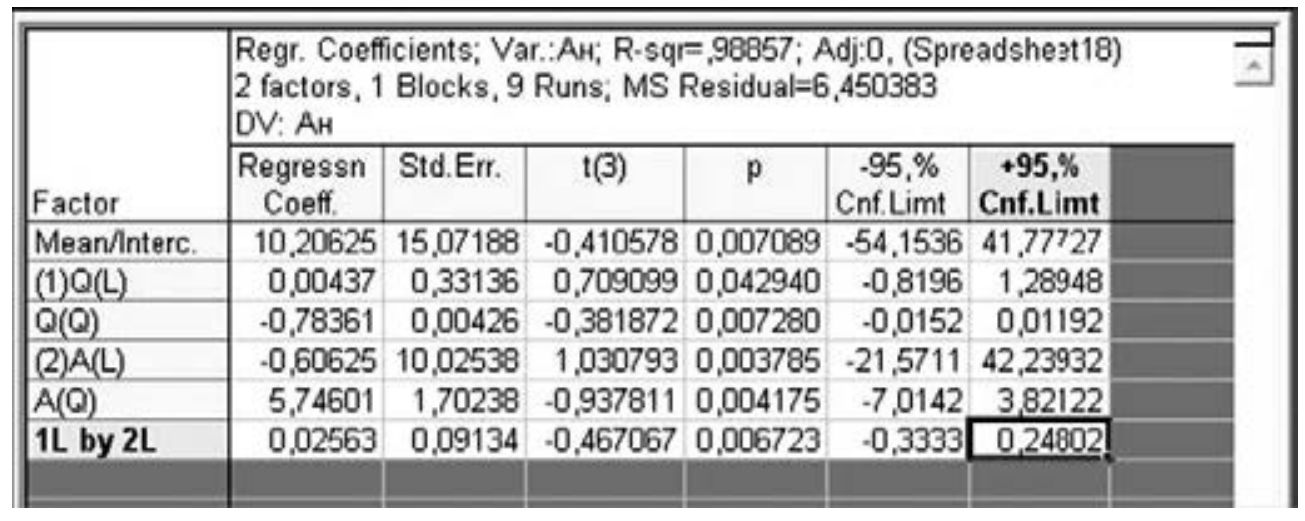

Figure 3. Analysis of experiment design-matrix (model 2) 


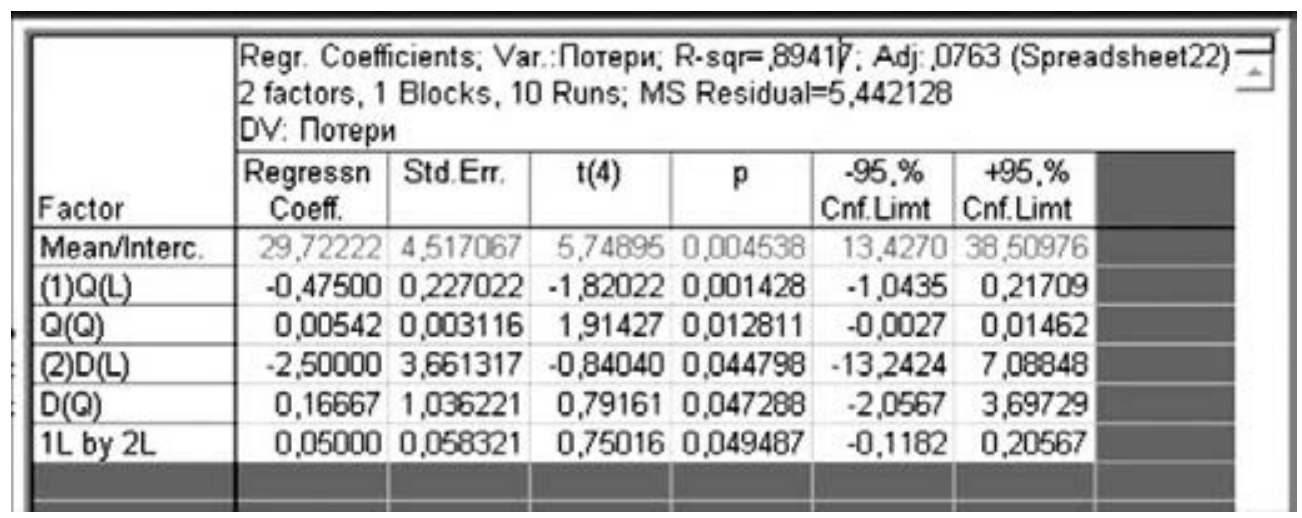

Figure 5. Experiment design-matrix and its realizing (model 3)

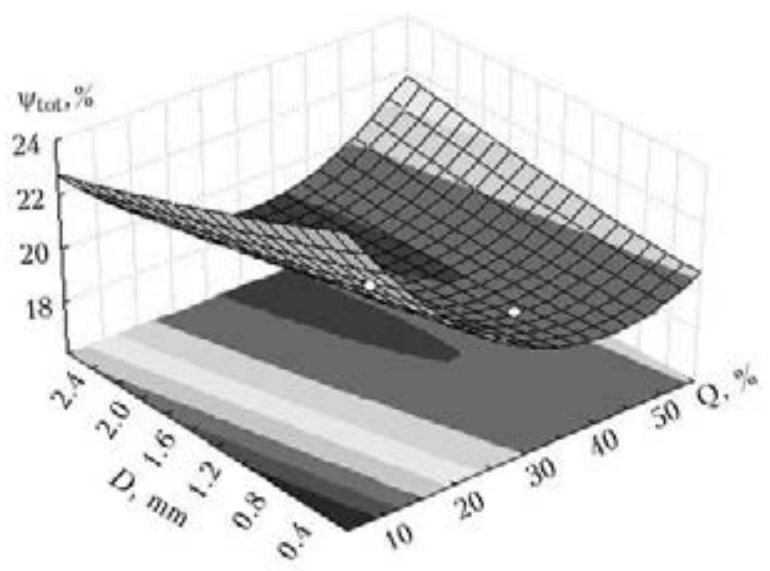

Figure 6. Dependence of coefficient of electrode metal loss $\psi$ tot on thickness of electrode coating $D$ and amount of exothermal mixture $Q$

Student's criterion; two last columns are the intervals for coefficients.

Regression equation looks like:

$$
\begin{gathered}
\alpha_{d}=10.20625+0.00437 Q-0.78361 Q^{2}- \\
-0.60625 A+5.7460 A^{2}+0.02563 A Q .
\end{gathered}
$$

Figure 4 shows response surface.

Model 3. Factors: amount of exothermal mixture $Q$ and thickness of electrode coating $D$; response is the loss coefficient $\psi_{\text {tot }}$. Figure 5 shows analysis of experiment plan-matrix.

It is seen from Figure 5 that all members of the model have statistically significant effects (level $p<0.05$ ). It also gives value of approximation reliability $R$-sqr $=0.89417-$ general quality of the model is good. Calculation of coefficients of regression is represented in the first column; $t(4)$ is the observed values of Student's criterion; $p$ is the significance of coefficients on Student's criterion; two last columns are the intervals for coefficients.

Regression equation looks like:

$$
\begin{gathered}
\psi_{\text {tot }}=29.72222-0.47500 Q+0.00542 Q^{2}- \\
-2.50000 \delta+0.16667 \delta^{2}+0.05000 Q \delta .
\end{gathered}
$$

Figure 6 shows response surface.

Analysis of obtained models showed that the optimum one is content of exothermal mixture in the amount of $35-40 \%$ at coating thickness $1.6 \mathrm{~mm}$ per side and scale to aluminum powder relationship 3:1. Such parameters provide for the lowest value of coefficient of electrode metal loss and deposition coefficient corresponds to set value in calculation of optimum content of exothermal mixture.

\section{Conclusion}

Statistical model is proposed. Its analysis shows that content of exothermal mixture in the amount of $35-40 \%$ is the optimum one at coating thickness $1.6 \mathrm{~mm}$ per side and 3:1 scale to aluminum powder relationship. Such parameters promote for the lowest value of coefficient of electrode metal loss and deposition coefficient corresponds to set value in calculation of optimum content of exothermal mixture.

1. Vlasov, A.F., Makarenko, N.A., Kushchy, A.M. (2014) Heating and melting of electrodes with exothermic mixture in coating. The Paton Welding J., $6 / 7,147-150$.

2. Vlasov, A.F., Kushchy, A.M. (2013) Improvement of high-efficient electrodes for manual arc welding and surfacing. In: Proc. of Int. Sci.-Techn. Conf. on University Science (Mariupol, GVUZ PGTU, 2013).

3. Yashcheritsyn, P.I. (1985) Planning of experiment in machine-building. Moscow: Mashinostroenie.

4. Spiridonov, A.A. (1981) Planning of experiment in examination of technological processes. Moscow: Mashinostroenie.

5. Zarubin, V.S. (2001) Mathematical modeling in technique: Manual for higher education institutions. Ed. by V.S. Zarubin, A.P. Krishchenko. Moscow: MGTU.

6. Borovikov, V.P. (2001) Statistica: Art of computer data analysis. For professionals. St.-Petersburg: Piter. 